\title{
ERRATUM
}

\section{Distribution of melt beneath Mount St Helens and Mount Adams inferred from magnetotelluric data}

Graham J. Hill, T. Grant Caldwell, Wiebke Heise, Darren G. Chertkoff, Hugh M. Bibby, Matt K. Burgess, James P. Cull and Ray A. F. Cas

Nature Geosci. 2, 785-789 (2009); published online: 25 October 2009; corrected online: 30 October 2009.

In the version of this Letter originally published, in Fig. 2 the elongated closed contour line should have been labelled +4 , as shown here. This error has been corrected in the HTML and PDF versions.

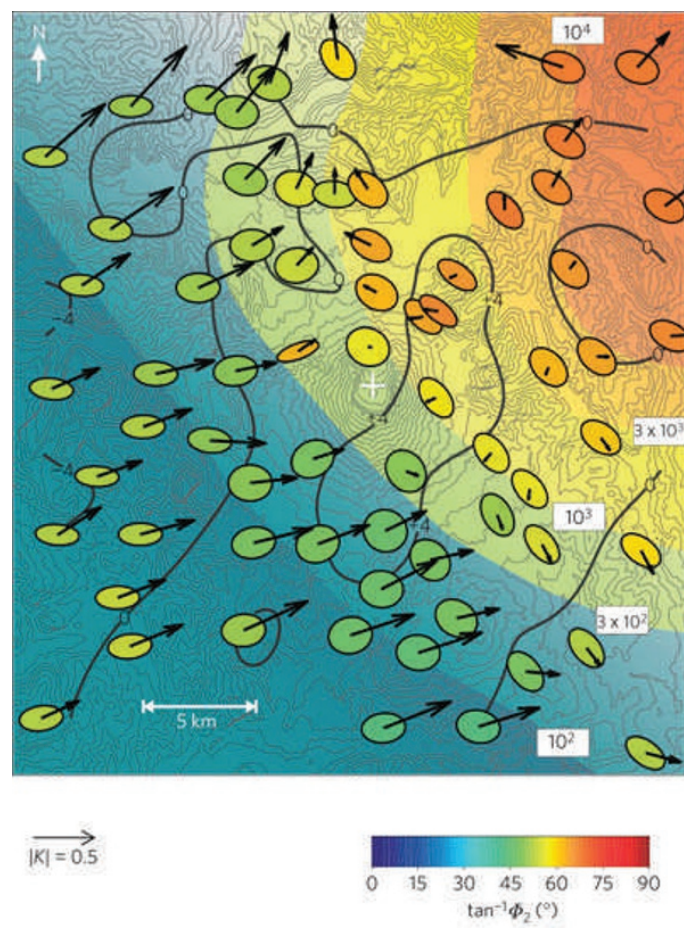

\section{ERRATUM}

Shrinking and splitting of drainage basins in orogenic landscapes from the migration of the main drainage divide

Stephane Bonnet

Nature Geosci. 2, 766-771 (2009); published online: 25 October 2009; corrected online: 28 October 2009.

In the version of this Letter originally published, in the second sentence of the abstract 'symmetric' should have been 'asymmetric'. This error has been corrected in the HTML and PDF versions of the text.

\section{CORRIGENDUM}

\section{Hydrothermal alteration and microfossil artefacts of the 3,465-million-year-old} Apex chert

Daniele L. Pinti, Raymond Mineau and Valentin Clement

Nature Geoscience 2, 640-643 (2009); published online: 2 August 2009; corrected after print: 22 November 2009.

It has been brought to our attention that the second sentence of the last paragraph on page 641 of this Letter and the sentence beginning "The microstructures are also present" in line 10 on page 642 of this Letter could be ambiguous. Both sentences have been amended in the HTML and PDF versions of the Letter. 